Article

\title{
Long-Term Stable Online Acetylene Detection by a CEAS System with Suppression of Cavity Length Drift
}

\author{
Qixin He *, Qibo Feng ${ }^{(D)}$ and Jiakun Li \\ MoE Key Lab of Luminescence and Optical Information, Beijing Jiaotong University, Beijing 100044, China; \\ qbfeng@bjtu.edu.cn (Q.F.); jkli@bjtu.edu.cn (J.L.) \\ * Correspondence: heqixin@bjtu.edu.cn; Tel.: +86-188-0121-7132
}

Received: 18 December 2018; Accepted: 21 January 2019; Published: 26 January 2019

check for updates

\begin{abstract}
A trace acetylene $\left(\mathrm{C}_{2} \mathrm{H}_{2}\right)$ detection system was demonstrated using the cavity-enhanced absorption spectroscopy (CEAS) technique and a near-infrared distributed feedback (NIR-DFB) laser. A Fabry-Perot (F-P) cavity with an effective optical path length of $49.7 \mathrm{~m}$ was sealed and employed as a gas absorption cell. Co-axis cavity alignment geometry was adopted to acquire a larger transmitted light intensity and a higher sensitivity compared with off-axis geometry. The laser frequency was locked to the cavity fundamental mode $\left(\mathrm{TEM}_{00}\right.$ mode) by using the Pound-Drever-Hall (PDH) technique continuously. By introducing a cavity length-locking loop, the drift of the cavity length was suppressed, and the stability of the system was enhanced. To demonstrate the efficacy of the system, a $\mathrm{C}_{2} \mathrm{H}_{2}$ absorption spectrum near $6534.36 \mathrm{~cm}^{-1}$ was acquired by tuning the laser operation temperature. Measurements of $\mathrm{C}_{2} \mathrm{H}_{2}$ samples with different concentrations were carried out, and a good linear relationship between $\mathrm{C}_{2} \mathrm{H}_{2}$ concentration and the cavity-transmitted signal voltage was observed. The measurement results showed the system could work stably for more than $2 \mathrm{~h}$ without major fluctuations. The Allan variance analysis results demonstrated a detection limit of 9 parts-per-billion (ppb) with an averaging time of $11 \mathrm{~s}$ corresponding to a minimum detectable absorption coefficient of $1.1 \times 10^{-8} \mathrm{~cm}^{-1}$.
\end{abstract}

Keywords: infrared absorption spectroscopy; cavity-enhanced absorption spectroscopy; gas sensor

\section{Introduction}

Acetylene $\left(\mathrm{C}_{2} \mathrm{H}_{2}\right)$ plays an important role in illumination, metal welding, and industrial production. The detection of trace $\mathrm{C}_{2} \mathrm{H}_{2}$ has attracted much attention due to its inflammable and explosive characteristics [1-3]. Furthermore, $\mathrm{C}_{2} \mathrm{H}_{2}$ is a kind of indicating gas dissolved in transformer oil. The monitoring of $\mathrm{C}_{2} \mathrm{H}_{2}$ concentration is of great significance for working state and performance evaluation of the transformer $[4,5]$. Among commonly used detection techniques for trace $\mathrm{C}_{2} \mathrm{H}_{2}$, resonant cavity-based infrared laser absorption spectroscopy techniques have attracted a lot of interest with the advantages of high detection sensitivity, fast response, and small sample volume. Techniques such as cavity ringdown spectroscopy (CRDS) [6-8] and cavity-enhanced absorption spectroscopy (CEAS) $[9,10]$ make use of high-finesse optical cavities that greatly increase the effective optical path length, thereby improving the detection sensitivity.

CRDS was proposed by Deacon and O'Keefe in 1988 [11]. In CRDS, the decay time of a light pulse trapped in the cavity is measured. By comparing the decay time of the empty cavity with that of the cavity filling with measured gas, the absorption coefficient can be obtained. Since the ring-down procedure occurrs in a fairly short period, CRDS highly depends on fast-response detection electronics, which limits its application [12,13]. Besides, the spectral resolution of CRDS is relatively low due to 
the use of pulsed lasers. Different from CRDS, CEAS measures the intensity of the transmitted light from the cavity by a photodetector, which reduces the response frequency requirement of the system. Many types of CEAS have been proposed, which can be divided into two categories: integrated cavity output spectroscopy (ICOS) [14-16] and mode-locking CEAS. In ICOS, the laser frequency is swept through some cavity modes, and the integrated transmission of these cavity modes is measured. The ICOS-based system is simple in structure, but the cavity transmission is greatly attenuated because of the inefficient injection of light into the cavity, and some noise can be introduced by the non-uniform excitation of the cavity modes [17]. The mode-locking CEAS was reported by Titus Gherman and Daniele Romanini in 2002 [18]. Mode-locked (ML) femtosecond pulsed lasers were used for CEAS in their paper, and the advantages were discussed. After that, mode-locking CEAS was used in a variety of applications by introducing different light sources. In 2008, Michael J. Thorpe et al. coupled the broad spectrum of a mode-locked fiber laser to an optical enhancement cavity to greatly enhance the detection sensitivity of breath samples [19]. In 2014, Chadi Abd Alrahman et al. demonstrated near-infrared cavity-enhanced optical frequency comb spectroscopy of water in a premixed methane/air flat flame. High-power throughput and stable cavity transmission were obtained in their experiment by tightly locking an Er:fiber comb to the cavity that contained the flame [20].

In this paper, a mode-locking CEAS-based system was presented for trace $\mathrm{C}_{2} \mathrm{H}_{2}$ measurement. A continuous-wave distributed feedback (DFB) laser centered at $1530.72 \mathrm{~nm}$ was locked to the cavity fundamental mode $\left(\mathrm{TEM}_{00}\right.$ mode) by the Pound-Drever-Hall (PDH) scheme [21] at all times, and the intensity of the cavity-transmitted light was measured continuously to characterize the gas concentration. Since the CEAS-based system did not have an absolute frequency reference, it was difficult to guarantee the long-term stability of the locking frequency. In our system, a new dual-channel feedback-locking loop is proposed to realize laser frequency locking and cavity length locking simultaneously. The drift of the cavity length was suppressed, and the stability of the system was enhanced. The paper is composed as follows. First, selection of the probe absorption line of $\mathrm{C}_{2} \mathrm{H}_{2}$ is reported. Then, the structure of the system and the design of key modules are introduced. Finally, gas detection experiments and the performance of the system are described.

\section{Absorption Line Selection}

The $\mathrm{C}_{2} \mathrm{H}_{2}$ molecule exhibits an overtone rotational-vibrational combination band $\left(\mathrm{v}_{1}+\mathrm{v}_{3}\right.$ band) around $6550 \mathrm{~cm}^{-1}$ as shown in Figure 1. The absorption line located at $6534.36 \mathrm{~cm}^{-1}$ (corresponding to $1530.37 \mathrm{~nm}$ ) was selected as the probe line to detect $\mathrm{C}_{2} \mathrm{H}_{2}$ in this system because of its relatively strong absorption intensity $\left(S=1.2 \times 10^{-20} \mathrm{~cm} /\right.$ molecule). Furthermore, the silica fiber has a lower transmission loss in this wavelength, which is suitable for the long-distance transmission of the laser and remote monitoring.

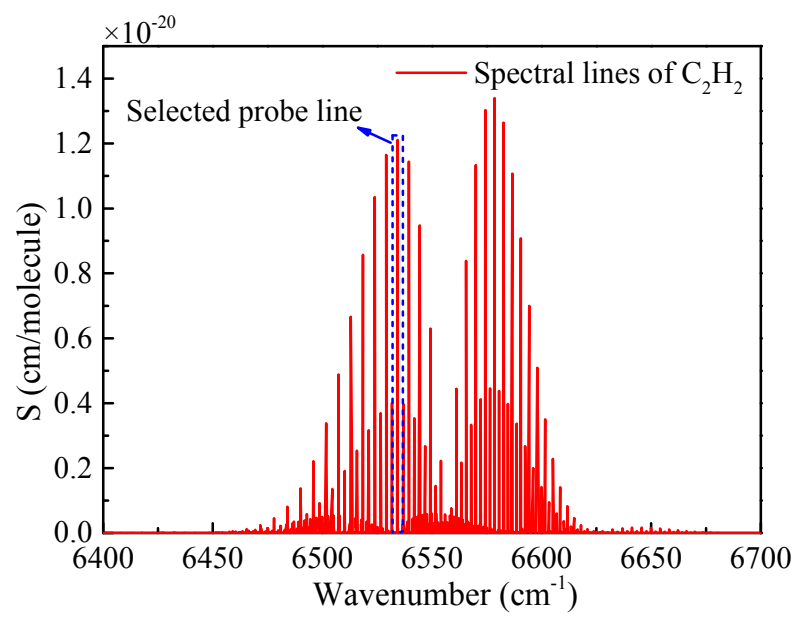

Figure 1. Spectral lines of acetylene $\left(\mathrm{C}_{2} \mathrm{H}_{2}\right)$ for a spectral range from $6400 \mathrm{~cm}^{-1}$ to $6700 \mathrm{~cm}^{-1}$. 
In order to avoid the interference caused by other major gases that exist in the air, the absorbance of the mixed gas of $\mathrm{C}_{2} \mathrm{H}_{2}(1 \mathrm{ppm})$ and air was simulated on the basis of data in the high-resolution transmission molecular absorption database 2012 (HITRAN 2012) [22]. The simulation was conducted in $1 \mathrm{~atm}, 298 \mathrm{~K}$, and a path length of $100 \mathrm{~cm}$. The absorbance of $1.8 \% \mathrm{H}_{2} \mathrm{O}$ is shown in Figure $2 \mathrm{a}$. The absorption intensity near $6534 \mathrm{~cm}^{-1}$ was in $10^{-4}$ level, which would influence the selectivity of the system. In order to eliminate this interference, a gas purifier (W.A. Hammond Drierite Co., L68GP) was installed before the cavity inlet, able to dry gases to a dryness of $0.005 \mathrm{mg} / 1$, under a flow rate of up to $300 \mathrm{~L}$ per hour. The absorbance of other gases present in the air had minimal interference in trace $\mathrm{C}_{2} \mathrm{H}_{2}$ detection, as shown in Figure $2 \mathrm{~b}$.

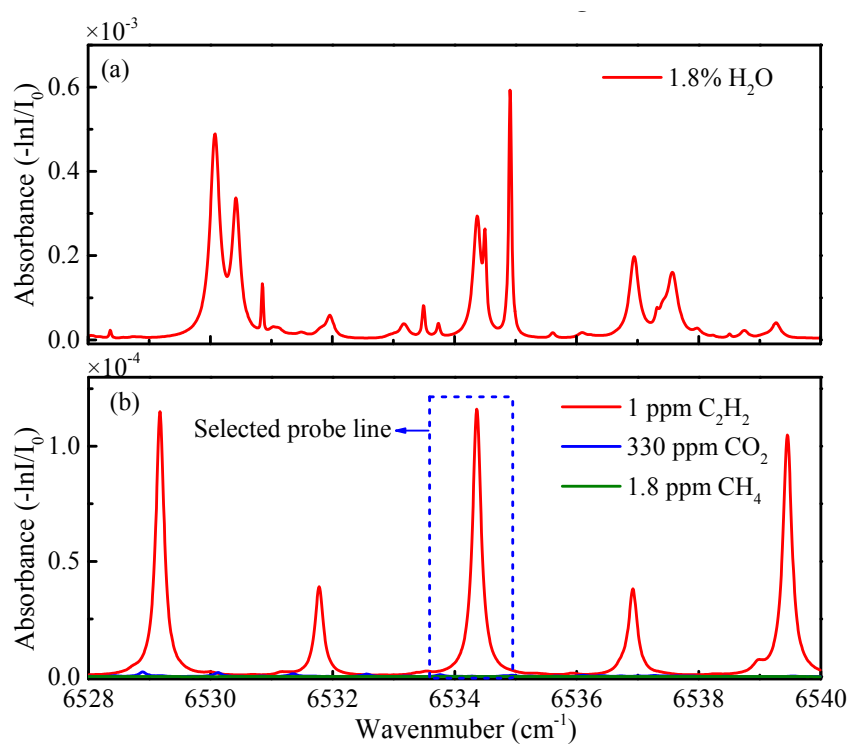

Figure 2. The absorbance of mixed gases from $6528 \mathrm{~cm}^{-1}$ to $6540 \mathrm{~cm}^{-1}$ at a simulation condition of $1 \mathrm{~atm}, 298 \mathrm{~K}$, and a path length of $100 \mathrm{~cm}$. (a) $1.8 \% \mathrm{H}_{2} \mathrm{O}$ (b) $1 \mathrm{ppm} \mathrm{C}_{2} \mathrm{H}_{2}, 330 \mathrm{ppm} \mathrm{CO}_{2}$, and 1.8 ppm $\mathrm{CH}_{4}$.

\section{System Structure and Design of Key Modules}

\subsection{Structure and Configuration}

The structure of the cavity-enhanced $\mathrm{C}_{2} \mathrm{H}_{2}$ sensor system is shown in Figure 3. It consists of two modules: the optical module and the electrical module.

(i) Optical module. A DFB laser produced by JDS Uniphase, model number CQF935/908-19570, was used as the optical source. The emission peak wavenumber of the laser is $6534.36 \mathrm{~cm}^{-1}(1530.72 \mathrm{~nm})$ at an operating temperature of $29^{\circ} \mathrm{C}$ and a driving current of $100 \mathrm{~mA}$, which was equal to the peak wavenumber of the selected probe absorption line. The laser is suitable for frequency modulation and locking with a high side-mode suppression ratio and a small linewidth (the linewidth at $-3 \mathrm{~dB}$ is better than $1 \mathrm{MHz}$ ). A fiber isolator (Thorlabs, IO-H-1550FC) was coupled to the laser output polarization-maintaining fiber to attenuate the optical feedback. The isolation of the isolator was $29 \mathrm{~dB}$ at a wavelength of $\sim 1.53 \mu \mathrm{m}$ according to the datasheet provided by the manufacturer. The output fiber of the isolator was coupled to a fiber collimator to convert the fiber-transmitted light into spatially transmitted light and narrow the light beam. The infrared beam passed through a polarizer and was guided into an electro-optic modulator (EOM) for laser frequency modulation. Then, the modulated light was directed to the self-developed cavity after passing through two mode-matching lenses (L5 and L6) and two three-dimensionally adjustable mirrors (M1 and M2). The cavity-transmitted light was focused onto an In-Ga-As detector (PD1, Thorlabs, PDA10CS) by a parabolic mirror (M3), and the cavity-reflected light was directed to another photodetector (PD2, QUBIG, PD-AC200) for laser-cavity frequency locking. 
(ii) Electrical module. The electrical part of the system included a commercial laser driver (Vescent photonics, D2-105-500), a three-channel piezoelectric transducer (PZT) controller (Thorlabs, MDT693), and a dual-feedback PDH locking loop. An EOM driver (QUBIG ADU, model 1 200MHz) was used for laser frequency modulation with a modulation frequency of $25 \mathrm{MHz}$. The cavity-reflected signal from PD2 was mixed with the local oscillator signal in the EOM driver and then filtered to produce the error signal. The error signal was processed by a proportional-integral-derivative (PID) controller 1 (TOPTICA, PID110) to generate a laser current feedback signal. Another PID controller was used in the cavity length-locking loop. A detailed description of the dual-feedback loop is presented in Section 3.4.

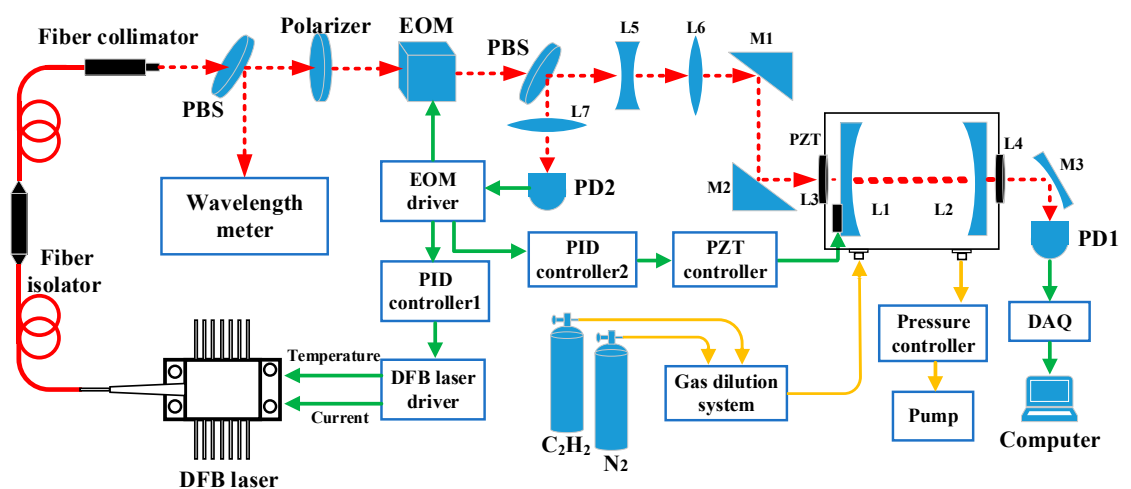

Figure 3. Structure of the frequency-locked cavity-enhanced absorption spectroscopy (CEAS)-based $\mathrm{C}_{2} \mathrm{H}_{2}$ detection system. The red lines represent optical pathways, the green lines represent electrical signal pathways, and the yellow lines are gas flow pathways. PD, photodiode; PBS, polarization beam splitter; DFB, distributed feedback; EOM, electro-optic modulator; PID, proportional-integral-derivative; PZT, piezoelectric transducer; DAQ, data acquisition; L1-7, lens 1-7; M1-3, mirror 1-3.

\subsection{Tuning Characteristics of the Laser}

The wavelength tuning characteristics of the DFB laser versus the driving current and the operation temperature were measured by a wavelength meter as shown in Figure 4 . The tuning index of the temperature was calculated to be $0.14 \mathrm{~nm} /{ }^{\circ} \mathrm{C}$, which was much larger than the tuning index of the driving current $(0.0015 \mathrm{~nm} / \mathrm{mA})$. Therefore, temperature tuning was adopted to move the wavelength to the desired one, and current tuning was used for PDH locking in this system. An operation temperature of $29^{\circ} \mathrm{C}$ combined with a driving current of $100 \mathrm{~mA}$ was selected to target the $1530.72 \mathrm{~nm} \mathrm{C}_{2} \mathrm{H}_{2}$ absorption line.

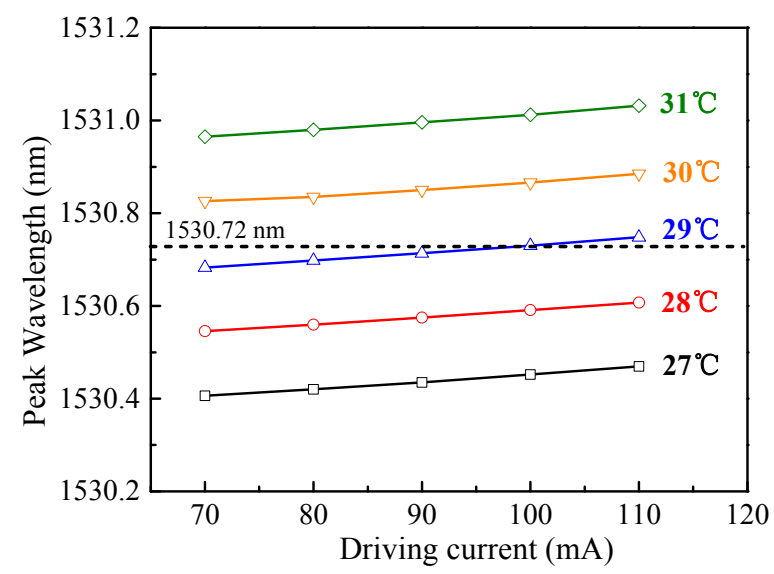

Figure 4. Tuning characteristics of the DFB diode laser. 


\subsection{Optical ModuleDdesign}

The stability condition of the cavity resonant field and the laser cavity mode matching are two main factors that need to be considered in the light path design [23]. For a linear F-P cavity with two concave mirrors, the stability condition is:

$$
0<\left(1-\frac{d}{r_{1}}\right)\left(1-\frac{d}{r_{2}}\right)<1
$$

where $r_{1}$ and $r_{2}$ are the ROC (radii of curvature) of the cavity mirrors, $d$ is the cavity length. In this system, the two cavity mirrors (EKSMA optics) with a same ROC of $100 \mathrm{~mm}$ and a calibrated reflectivity of $99.4 \%$ at $1.54 \mu \mathrm{m}$ were spaced by a $15 \mathrm{~cm}$ distance. The specifications of the designed cavity were calculated as shown in Table 1.

The mode-matching system was designed to match the spatial distribution of the light beam to the mode distribution of the cavity and obtain a stable and pure fundamental transverse mode in the cavity. In the system, the light passed through a fiber collimator to shape the beam profile and adjust the direction of the exit light. The divergence angle of the fiber collimator varied with the laser wavelength. When the incident laser wavelength was $1530.7 \mathrm{~nm}$, the divergence angle was $0.1294^{\circ}$, and the beam waist radius of the collimated light was calculated to be $219 \mu \mathrm{m}$. A concave lens (L5) and a convex lens (L6) were added to the optical path to adjust the beam waist radius. The focal lengths of the two lenses and the lens spacing distances were calculated to generate the correct beam parameters and leave sufficient space for installing other optical components. Two three-dimensionally adjustable mirrors (M1 and M2) were used to adjust the direction and position of the incident laser.

Table 1. Basic specifications of the designed cavity. FSR, free spectral range.

\begin{tabular}{ccc}
\hline & Symbol & Value \\
\hline Cavity length & $L$ & $15 \mathrm{~cm}$ \\
Reflectivity & $R$ & $99.4 \%$ \\
FSR & $f_{F S R}$ & $1 \mathrm{GHz}$ \\
Linewidth & $\Delta v_{c}$ & $1.92 \mathrm{MHz}$ \\
Finesse & $f$ & 520.8 \\
Equivalent Absorption length & $L_{e f f}$ & $49.7 \mathrm{~m}$ \\
\hline
\end{tabular}

\subsection{Electro-Optic Modulation-Based PDH Locking Scheme}

The dual-feedback locking loop was designed to consist of a PDH locking loop and a cavity length-locking loop, as shown in Figure 5. The electro-optic modulation-based PDH locking loop consisted of an EOM module, a PID controller (PID1), and a laser current control module, which realized the active feedback control of the laser frequency. A $25 \mathrm{MHz}$ sinusoidal signal with a small modulation index was generated by the advanced drive unit (ADU) to modulate the laser frequency. The modulated light entered the cavity and experienced multiple reflections. After that, a portion of light returned from the cavity along the incident path and was collected by the photodetector PD2. This reflected light signal was filtered by a high-pass filter with a cutoff frequency of $200 \mathrm{MHz}$ and multiplied by the phase-shifted reference signal in the EOM driver. Then, an error signal was generated after a low-pass filter (cutoff frequency is $1.9 \mathrm{MHz}$ ), which could represent the phase difference between the laser frequency and the cavity resonance frequency. The error signal was then processed by the PID controller (PID1), and a control signal was generated and fed back to the laser current driver for the mode locking between laser and cavity.

To observe the cavity resonance, a periodic sawtooth wave signal was applied to the PZT driver to sweep the cavity length. The measured cavity transmission signal and PDH error signal were captured by an oscilloscope (Tektronix, MDO4104B-6), as shown in Figure 6a. The green line represents the PZT sweep signal, the red line represents the error signal, and the blue line represents the cavity-transmitted signal. The error signal is centered symmetrically and contains a steep linear region near resonance. 
Figure $6 \mathrm{~b}$ shows the cavity transmission facula captured by an infrared imager (Electrophysics, PV320). The laser was resonantly coupled to the fundamental mode, and all other high modes in the cavity were eliminated.

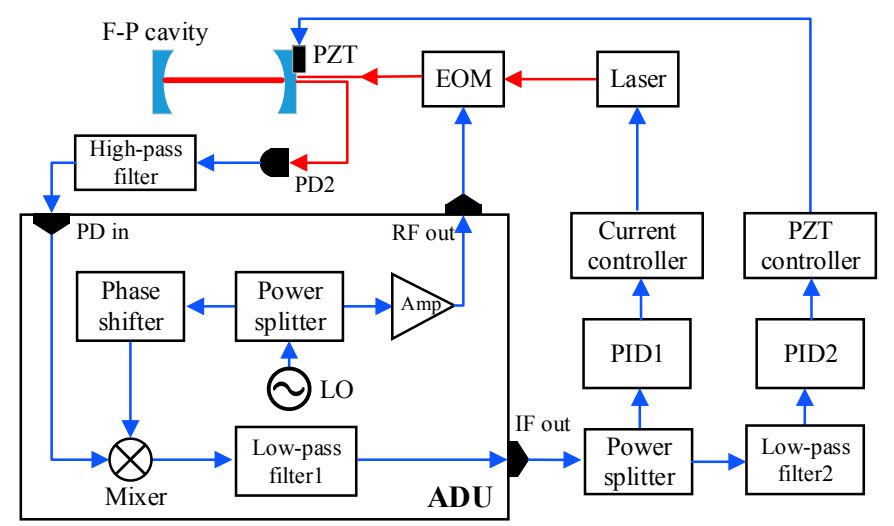

Figure 5. The scheme of the dual-feedback locking loop. LO, Local oscillator; ADU, advanced drive unit; F-P, Fabry-Perot; RF, radio frequency; IF, intermediate frequency.

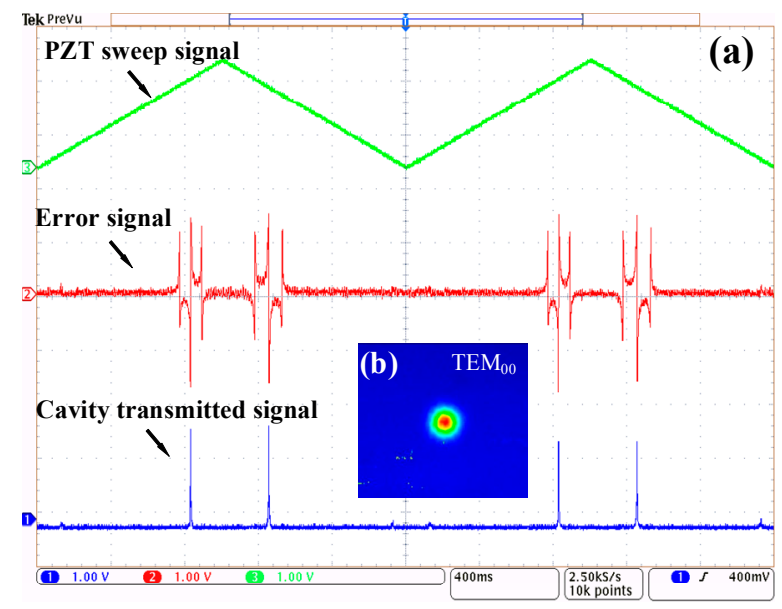

Figure 6. Cavity resonance under critical coupling conditions. (a) The green line represents the PZT sweep signal, the red line represents the error signal, and the blue line represents the cavity-transmitted signal. (b) Cavity transmission facula.

\subsection{Cavity Length Feedback Locking}

The optical cavity was used as the reference frequency standard in this system, and the stability of the cavity length determined the performance of the system. During the operation of the system, the cavity experienced a slow frequency drift on cavity length due to variations in the environment (such as temperature, pressure) [24]. This drift caused the deviation of the locked laser frequency from the center of the probe absorption line. In addition, the effective optical path was also changed, causing measurement errors. As shown in Figure 7a, when the laser was locked to the cavity, the transmitted signal was stable, and the mean value of the error signal voltage was close to zero. Without cavity length locking, after $10 \mathrm{~min}$ of operation, the fluctuation of the transmitted signal was 15.3 times larger, and the mean value of the error signal changed to $-7.7 \mathrm{mV}$ due to the incomplete locking caused by cavity length drift, as shown in Figure $7 \mathrm{~b}$.

In order to eliminate the offset of the error signal, a cavity length feedback locking loop was designed, as shown in Figure 5. The controlled object of this feedback loop was the distance between the two cavity mirrors. A PZT was mounted between the incident mirror and the mount with a maximum length variation of $2.5 \mu \mathrm{m}$. The low frequency drift of the error signal was extracted by a low-pass filter (low-pass filter 2) with a cutoff frequency of $1 \mathrm{~Hz}$ and directed to a PID controller 
(PID2) to generate a feedback control signal to the PZT driver. The cavity length was then adjusted to suppress the drift.

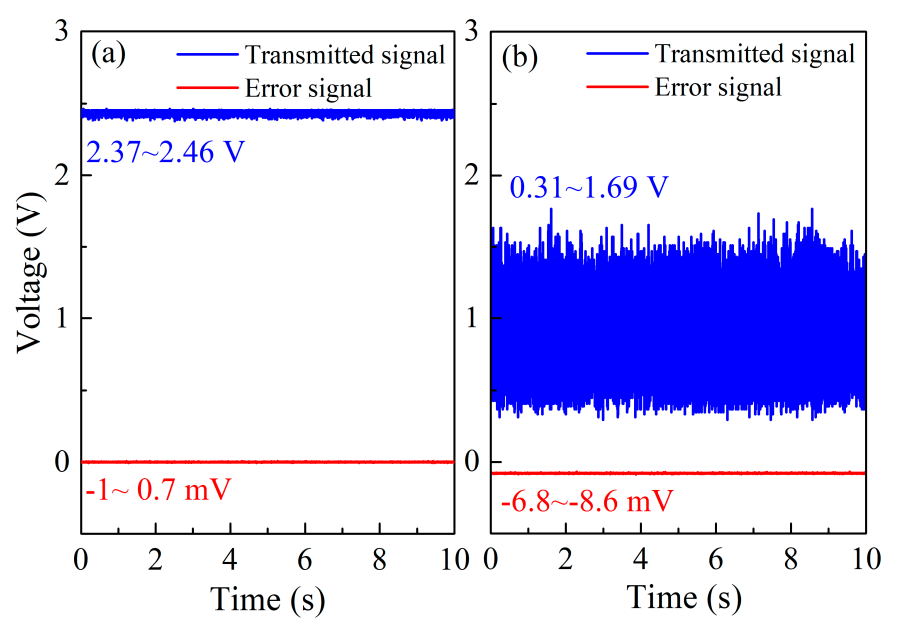

Figure 7. Cavity-transmitted signal and error signal under different conditions. (a) The laser is locked to the cavity; (b) the laser and cavity are unlocked.

\section{Experiment and Results}

In order to achieve the environmental stabilization of the system, some measures were taken to reduce mechanical and acoustic vibrations, pressure variations, and temperature fluctuations. The experiment platform was established in a $23^{\circ} \mathrm{C}$ thermostatically controlled laboratory. The optical components of the system were fixed to a pressurized air-floating optical table to reduce mechanical noise. The acoustic isolation was provided by a layer of fiberglass insulation wrapped around the cavity. The gas pressure inside the cavity was controlled to be $1 \mathrm{~atm}$ during the gas detection measurement by the pressure control module, which consisted of an air pump (KNF lab, model N813.5) and a pressure controller (MKS, type 640). $\mathrm{C}_{2} \mathrm{H}_{2}$ samples with different concentrations were generated by a gas dilution system (Environics, Model 4040), which could produce gas concentrations from percent to $\mathrm{ppb}$ levels for single- or multi-point calibration with an accuracy of $\pm 1.0 \%$. All experiments were performed at night to make sure the vibration and acoustic noise levels in the lab were at a minimum.

\section{1. $\mathrm{C}_{2} \mathrm{H}_{2}$ Absorbance Measurements}

In the experiment, the $\mathrm{C}_{2} \mathrm{H}_{2}$ sample with a concentration of $10 \mathrm{ppm}$ balanced with pure $\mathrm{N}_{2}$ was pumped into the cavity. The pressure and temperature of the gas were 700 Torr $(0.92 \mathrm{~atm})$ and $23^{\circ} \mathrm{C}$, respectively. In order to make sure the laser wavelength swept across the selected $\mathrm{C}_{2} \mathrm{H}_{2}$ absorption line near $6534.36 \mathrm{~cm}^{-1}$, the DFB laser current was set to $100 \mathrm{~mA}$, corresponding to a laser power of 18 $\mathrm{mW}$, and the laser operation temperature was modulated from $33.5^{\circ} \mathrm{C}$ to $33.7^{\circ} \mathrm{C}$ in steps of $0.012{ }^{\circ} \mathrm{C}$, which resulted in the emission peak wavenumber changed from $6533.78 \mathrm{~cm}^{-1}$ to $6534.93 \mathrm{~cm}^{-1}$ in steps of $0.084 \mathrm{~cm}^{-1}$. The laser cavity frequency locking at each wavenumber included two steps. Firstly, the cavity length was adjusted by the PZT driver to make the laser frequency and the cavity resonant frequency roughly the same. Then, the laser frequency was locked to the cavity resonant frequency by a negative feedback current adjustment. The sampling rate of the system was set to $10 \mathrm{~Hz}$, which resulted in 10 data points per second. The average cavity transmission signal voltage within $10 \mathrm{~s}$ of each wave number acquired is shown in Figure 8. When the locking wavenumber was equal to $6534.36 \mathrm{~cm}^{-1}$, the absorption was in the strongest position, corresponding to an operation temperature of $29^{\circ} \mathrm{C}$. 


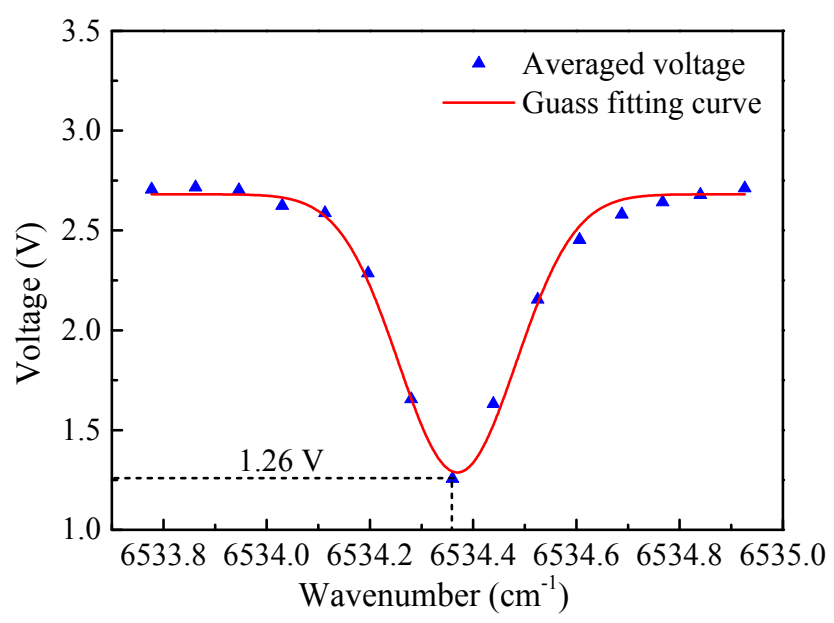

Figure 8. Absorption spectrum of $10 \mathrm{ppm}_{2} \mathrm{H}_{2}$.

\subsection{Calibration and Stability}

The cavity-transmitted signal voltage was measured at different $\mathrm{C}_{2} \mathrm{H}_{2}$ concentrations ( $2 \mathrm{ppm}$, 4 ppm, 6 ppm, 8 ppm, 10 ppm). At each concentration level, the voltage was recorded for $5 \mathrm{~min}$. The relation between $\mathrm{C}_{2} \mathrm{H}_{2}$ concentration and averaged transmitted signal voltage was acquired as depicted in Figure 9 and confirmed a linear response of the system $\left(R^{2}=0.997\right)$.

The linear fitting equation is:

$$
V(\mathrm{~V})=2.44-0.12 \times C(\mathrm{ppm})
$$

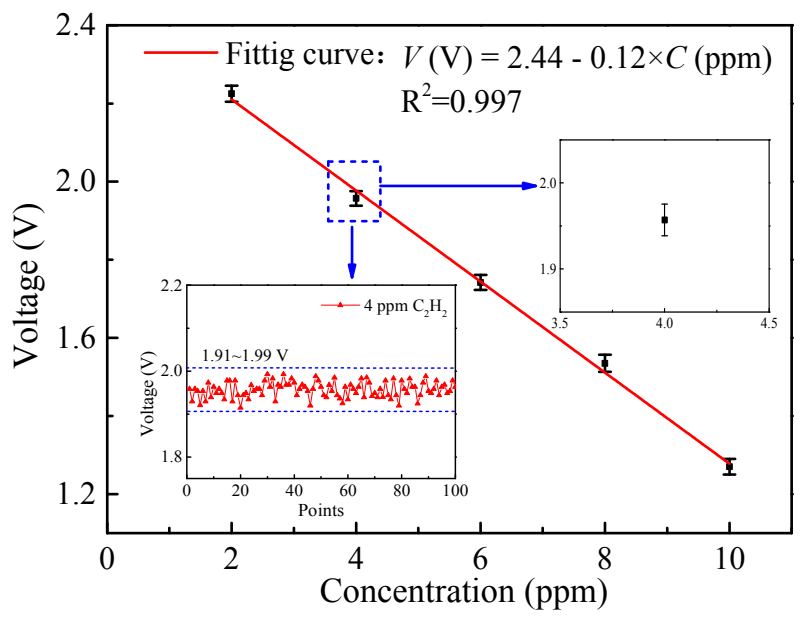

Figure 9. Fitting curve of the cavity-transmitted signal voltage versus $\mathrm{C}_{2} \mathrm{H}_{2}$ concentration. The lower inset shows the measurement results of $4 \mathrm{ppm} \mathrm{C}_{2} \mathrm{H}_{2}$, and the upper inset shows the error bar of the results.

In order to avoid errors caused by the gas distribution system, the stability of the system was investigated by a long-term measurement of pure $\mathrm{N}_{2}$. The measurement lasted for $2 \mathrm{~h}$ with a sampling rate of $10 \mathrm{~Hz}$, providing 36000 sampling points, calculated as shown in Figure 10a. The system worked steadily and stably during the measurement process without major fluctuations. The limit of detection (LoD) of the system was characterized by Allan deviation analysis as shown in Figure 10b. A LoD of $137 \mathrm{ppb}$ was obtained at an averaging time of $0.1 \mathrm{~s}$ which could be further improved to $9 \mathrm{ppb}$ by increasing the averaging time to $11 \mathrm{~s}$. The LOD was valid in a dry gas, free from water. 

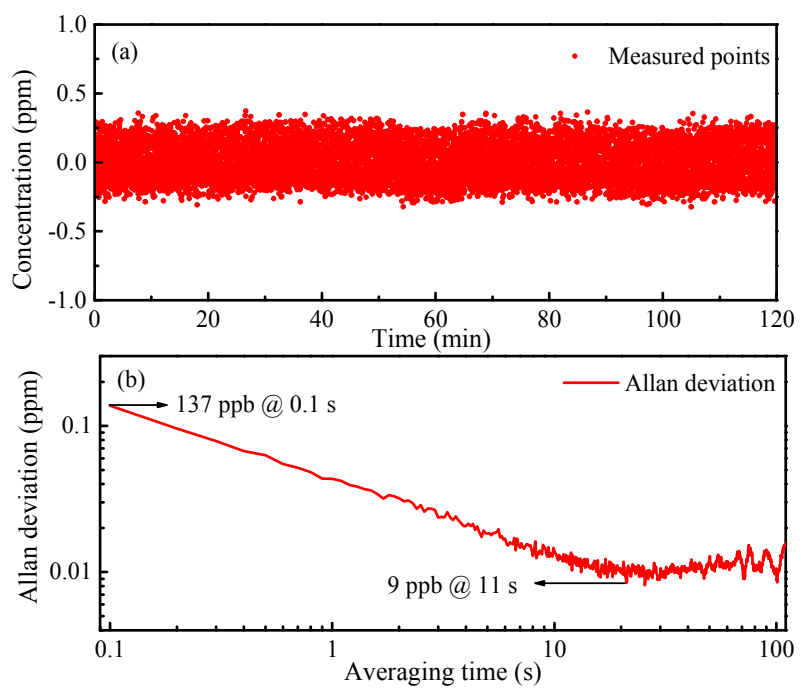

Figure 10. (a) Measured concentration of a 0 ppm $\mathrm{C}_{2} \mathrm{H}_{2}$ sample; (b) Allan deviation analysis of the sensor system.

\section{Comparison and Conclusion}

The comparison among this system and other reported $\mathrm{C}_{2} \mathrm{H}_{2}$ detection systems is shown in Table 2. It was found that the LoD of this system was $9 \mathrm{ppb}$, which is competitive compared with other reported systems using near-infrared laser sources. Compared to other systems, this sensor system reached a longer effective optical path length $(49.7 \mathrm{~m})$ by a compact cavity with a simple structure and small volume. Furthermore, the effective path length could be easily improved by increasing the reflectivity of the cavity mirrors without increasing the technical complexity. Compared to other mode-locking CEAS based systems, a novel cavity length feedback locking loop was introduced in this system to reduce the cavity length drift, which led to good experimental results.

Table 2. Comparison between this system and other reported $\mathrm{C}_{2} \mathrm{H}_{2}$ detection systems. LoD, limit of detection; ICL, interband cascade lasers.

\begin{tabular}{ccccc}
\hline Refs. & Principal & Source Type & Optical Path & LoD \\
\hline$[2]$ & QEPAS & DFB $(1.53 \mu \mathrm{m})$ & $/$ & $2 \mathrm{ppm}$ \\
{$[3]$} & TDLAS & DFB $(1.53 \mu \mathrm{m})$ & $30 \mathrm{~cm}$ & $540 \mathrm{ppb}$ \\
{$[25]$} & TDLAS & ICL $(3.026 \mu \mathrm{m})$ & $20.4 \mathrm{~cm}$ & $1 \mathrm{ppb}$ \\
{$[26]$} & TDLAS & DFB $(1.53 \mu \mathrm{m})$ & $10.1 \mathrm{~m}$ & $0.49 \mathrm{ppm}$ \\
{$[27]$} & OA-ICOS & DFB $(1.53 \mu \mathrm{m})$ & $9.28 \mathrm{~m}$ & $85 \mathrm{ppb}$ \\
This paper & CEAS & DFB $(1.53 \mu \mathrm{m})$ & $49.7 \mathrm{~m}$ & $9 \mathrm{ppb}$ \\
\hline
\end{tabular}

In conclusion, we have developed and characterized a frequency-locked CEAS technique-based $\mathrm{C}_{2} \mathrm{H}_{2}$ sensor system in the near-infrared region. An effective optical path length of $49.7 \mathrm{~m}$ was obtained by a $15 \mathrm{~cm}$ long cavity. We proposed a dual-feedback locking loop to realize laser frequency locking and cavity length locking simultaneously, which reduced the drift of the cavity length and enhanced measurement stability. A series of $\mathrm{C}_{2} \mathrm{H}_{2}$ detection experiments were carried out, and the results showed the system could work stably for more than $2 \mathrm{~h}$ without major fluctuations. The limit of detection of this system reached $137 \mathrm{ppb}$ at an averaging time of $0.1 \mathrm{~s}$, which could be further improved to $9 \mathrm{ppb}$ by increasing the averaging time to $11 \mathrm{~s}$.

Author Contributions: Conceptualization, Q.H., Q.F. and J.L.; Software, Q.H. and J.L.; Validation, Q.H. and Q.F.; Data Curation, Q.H.; Writing-Original Draft Preparation, Q.H.; Writing-Review \& Editing, Q.H., Q.F. and J.L.; Funding Acquisition, Q.H. and Q.F.

Funding: This work was supported by the National Natural Science Foundation of China-Major Program (51527806) and the Fundamental Research Funds for the Central Universities (2019RC002). 
Conflicts of Interest: The authors declare no conflict of interest.

\section{References}

1. Utsav, K.C.; Nasir, E.F.; Farooq, A. A mid-infrared absorption diagnostic for acetylene detection. Appl. Phys. B 2015, 120, 223-232.

2. Cao, Y.; Jin, W.; Ho, H.L.; Qi, L.; Yang, Y.H. Acetylene detection based on diode laser QEPAS: Combined wavelength and residual amplitude modulation. Appl. Phys. B 2012, 109, 359-366. [CrossRef]

3. He, Q.X.; Zheng, C.T.; Liu, H.F.; Bin Li, B.; Wang, Y.D.; Tittel, F.K. Performance improvement of a near-infrared acetylene sensor system by reducing residual amplitude modulation. Laser Phys. 2017, 27, 055702. [CrossRef]

4. Ghoneim, S.S.M.; Taha, I.B.M. A new approach of DGA interpretation technique for transformer fault diagnosis. Int. J. Electr. Power 2016, 81, 265-274. [CrossRef]

5. Wu, Z.Y.; Gong, Y.H.; Yu, Q.X. Photoacoustic spectroscopy detection and extraction of discharge feature gases in transformer oil based on $1.5 \mathrm{mu}$ tunable fiber laser. Infrared Phys. Technol. 2013, 58, 86-90. [CrossRef]

6. Banik, G.D.; Som, S.; Maity, A.; Pal, M.; Maithani, S.; Mandal, S.; Pradhan, M. An EC-QCL based N2O sensor at $5.2 \mathrm{mu} \mathrm{m}$ using cavity ring-down spectroscopy for environmental applications. Anal. Methods-UK 2017, 9, 2315-2320. [CrossRef]

7. Zhou, S.; Han, Y.L.; Li, B.C. Pressure optimization of an EC-QCL based cavity ring-down spectroscopy instrument for exhaled NO detection. Appl. Phys. B. 2018, 124, 27. [CrossRef]

8. Maity, A.; Pal, M.; Banik, G.D.; Maithani, S.; Pradhan, M. Cavity ring-down spectroscopy using an EC-QCL operating at $7.5 \mathrm{mu} \mathrm{m}$ for direct monitoring of methane isotopes in air. Laser Phys. Lett. 2017, 14, 115701. [CrossRef]

9. Markus, C.R.; Perry, A.J.; Hodges, J.N.; McCall, B.J. Improving cavity-enhanced spectroscopy of molecular ions in the mid-infrared with up-conversion detection and Brewster-plate spoilers. Opt. Express 2017, 25, 3709-3721. [CrossRef]

10. Baran, S.G.; Hancock, G.; Peverall, R.; Ritchie, G.A.D.; van Leeuwen, N.J. Optical feedback cavity enhanced absorption spectroscopy with diode lasers. Analyst 2009, 134, 243-249. [CrossRef]

11. Okeefe, A.; Deacon, D.A.G. Cavity Ring-down Optical Spectrometer for Absorption-Measurements Using Pulsed Laser Sources. Rev. Sci. Instrum. 1988, 59, 2544-2551. [CrossRef]

12. Nadeem, F.; Postma, B.R.; Postma, G.; Cristescu, S.M.; Mandon, J.; Harren, F.J.M. Comprehensive three-dimensional ray tracing model for three-mirror cavity-enhanced spectroscopy. Appl. Opt. 2018, 57, 154-163. [CrossRef] [PubMed]

13. Kasyutich, V.L.; Canosa-Mas, C.E.; Pfrang, C.; Vaughan, S.; Wayne, R.P. Off-axis continuous-wave cavity-enhanced absorption spectroscopy of narrow-band and broadband absorbers using red diode lasers. Appl. Phys. B 2002, 75, 755-761. [CrossRef]

14. Tan, Z.Q.; Long, X.W.; Feng, X.W.; Wei, Z.M. The study of wavelength modulation off-axis integrated cavity output spectroscopy in the case of Lorentzian absorption profile. Opt. Commun. 2011, 284, 852-856. [CrossRef]

15. Miller, J.H.; Bakhirkin, Y.A.; Ajtai, T.; Tittel, F.K.; Hill, C.J.; Yang, R.Q. Detection of formaldehyde using off-axis integrated cavity output spectroscopy with an interband cascade laser. Appl. Phys. B. 2006, 85, 391-396. [CrossRef]

16. Centeno, R.; Mandon, J.; Cristescu, S.M.; Harren, F.J.M. Sensitivity enhancement in off-axis integrated cavity output spectroscopy. Opt. Express 2014, 22, 27985-27991. [CrossRef]

17. Morville, J.; Kassi, S.; Chenevier, M.; Romanini, D. Fast, low-noise, mode-by-mode, cavity-enhanced absorption spectroscopy by diode-laser self-locking. Appl. Phys. B. 2005, 80, 1027-1038. [CrossRef]

18. Gherman, T.; Romanini, D. Mode-locked cavity-enhanced absorption spectroscopy. Opt. Express 2002, 10, 1033-1042. [CrossRef]

19. Thorpe, M.J.; Clausen, D.B.; Kirchner, M.S.; Ye, J. Cavity-enhanced optical frequency comb spectroscopy: Application to human breath analysis. Opt. Express 2008, 16, 2387-2397. [CrossRef]

20. Alrahman, C.A.; Khodabakhsh, A.; Schmidt, F.M.; Qu, Z.; Foltynowicz, A. Cavity-enhanced optical frequency comb spectroscopy of high-temperature $\mathrm{H}_{2} \mathrm{O}$ in a flame. Opt. Express 2014, 22, 13889-13895. [CrossRef]

21. Su, J.; Jiao, M.X.; Jiang, F. Pound-Drever-Hall laser frequency locking technique based on orthogonal demodulation. Optik 2018, 168, 348-354. 
22. Rothman, L.S.; Gordon, I.E.; Babikov, Y.; Barbe, A.; Benner, D.C.; Bernath, P.F.; Birk, M.; Bizzocchi, L.; Boudon, V.; Brown, L.R.; et al. The HITRAN2012 molecular spectroscopic database. J. Quant Spectrosc. Radiat. 2013, 130, 4-50. [CrossRef]

23. Kogelnik, H.; Li, T. Laser Beams and Resonators. Appl. Opt. 1966, 5, 1550-1567. [CrossRef] [PubMed]

24. Hagel, G.; Houssin, M.; Knoop, M.; Champenois, C.; Vedel, M.; Vedel, F. Long-term stabilization of the length of an optical reference cavity. Rev. Sci. Instrum. 2005, 76, 123101. [CrossRef]

25. $\mathrm{Mu}, \mathrm{Y} . ; \mathrm{Hu}, \mathrm{T} . L . ;$ Gong, H.; Ni, R.W.; Li, S.J. A Trace $\mathrm{C}_{2} \mathrm{H}_{2}$ Sensor Based on an Absorption Spectrum Technique Using a Mid-Infrared Interband Cascade Laser. Micromachines 2018, 9, 530. [CrossRef] [PubMed]

26. Ma, G.M.; Zhao, S.J.; Jiang, J.; Song, H.T.; Li, C.R.; Luo, Y.T.; Wu, H. Tracing Acetylene Dissolved in Transformer Oil by Tunable Diode Laser Absorption Spectrum. Sci. Rep. 2017, 7, 14961. [CrossRef] [PubMed]

27. Zheng, K.Y.; Zheng, C.T.; He, Q.X.; Yao, D.; Hu, L.; Zhang, Y.; Wang, Y.D.; Tittel, F.K. Near-infrared acetylene sensor system using off-axis integrated-cavity output spectroscopy and two measurement schemes. Opt. Express 2018, 26, 26205-26216. [CrossRef]

(C) 2019 by the authors. Licensee MDPI, Basel, Switzerland. This article is an open access article distributed under the terms and conditions of the Creative Commons Attribution (CC BY) license (http:/ / creativecommons.org/licenses/by/4.0/). 